ISSN: 1980-055X

Recebido em: 30/04/2010

Aceito para publicação em: 26/07/2010

\title{
INFLUÊNCIA DA PRECIPITAÇÃO NOS MANGUEZAIS DA BARRA DO RIBEIRA - IGUAPE/SP
}

\author{
Nádia G. B. de Lima ${ }^{16}$ \\ Emerson Galvani ${ }^{17}$.
}

\begin{abstract}
RESUMO
O manguezal, definido como um ecossistema costeiro de transição entre os ambientes terrestres e marinhos caracteriza-se por ambiente salinizado e pela constante inundação causada por marés. Com destaque na área do Sistema Costeiro Cananéia - Iguape, sua importância maior está relacionada à produção de biomassa, inserida no sistema bioenergético natural, aumentando a produtividade da zona costeira com a introdução de particulados orgânicos. Representam comunidades vegetais adaptadas a várias condicionantes físicas atuantes nas zonas costeiras, entre elas, as climáticas. O presente artigo faz parte de um trabalho maior, que tem como objetivo contribuir com 0 entendimento da variação dos atributos climáticos e sua influência na vegetação do manguezal. No entanto, aqui serão apresentados os dados e as análises do atributo precipitação, bem como a interceptação da precipitação pelo dossel do manguezal, localizado na Barra do Ribeira-Iguape/SP. Para isso, foi instalada uma torre microclimática contendo duas estações meteorológicas, com um pluviômetro cada, de forma a obter uma análise da variação da precipitação acima e abaixo do dossel de manguezal. Além de 16 pluviômetros totalizadores ao longo de uma área de $400 \mathrm{~m}^{2}$. Verificou-se que, na escala de trabalho microclimática, o dossel é o principal controle para a variação dos atributos climáticos, principalmente na distribuição pluviométrica abaixo desse dossel, o que, consequentemente, influencia na distribuição das espécies vegetais do ambiente. Constatou-se que a quantidade de precipitação que efetivamente atinge o solo e a forma com que ela é redistribuída dentro do ambiente depende da densidade do dossel e de suas ramificações de galhos e caule. Para o manguezal esse processo é importante, visto que a quantidade de chuva que efetivamente atinge o solo contribuir para a diminuição da salinidade presente no ambiente, sendo determinante para o tipo de espécie predominante no
\end{abstract}

\footnotetext{
${ }^{16}$ Mestre em Geografia Física. Departamento de Geografia - USP, Av. Lineu Prestes, XXX, Cidade Universitária. Email: nadia.lima@usp.br

17 Prof. Doutor do Departamento de Geografia - USP, Av. Lineu Prestes, XXX, Cidade Universitária. E-mail: egalvani@usp.br
} 
manguezal. Esse projeto foi financiamento pelo $\mathrm{CNPq}$, processo número 470434/2006-6 referente ao edital MCT/CNPq 02/2006 - Universal.

Palavra-chaves: mangue, atributos climáticos, dossel, precipitação, interceptação.

\section{ABSTRACT}

The mangrove, coastal ecosystem defined as a transition between terrestrial and marine environment is characterized as a salinized environment with a constant flooding caused by tides. Emphasizing the System area Coastal Cananéia - Iguape, its importance is related to the biomass production, inserted into the natural bioenergetics system, increasing the productivity of the coastal zone with the introduction of organic particles. This means vegetal communities are adapted to many physical conditionants the active in the coastal zones, including the climate conditionants. This article is part of a larger work, which purpose is contributes to the comprehension of variability of the climatic attributes and their influence on the mangrove vegetation. Here are presented the data and analysis of the precipitation and interception of rain by the canopy of the mangrove forest located in Barra do Ribeira-Iguape/SP. A microclimatic tower was installed with two meteorological stations and each one had rain gauge to obtain an analysis of the variation of precipitation above and below the canopy of mangrove. More sixteen rain gauges were installed in an area of 400 $\mathrm{m}^{2}$. Our research results shows that in microclimatic scales the main control for the variation of climatic attributes is the canopy, mainly in rainfall distribution below the canopy, which consequently influences in the distribution of vegetables species in the environment. It was found also that the amount of rainfall that effectively reaches the ground and how this is redistributed within the environment depends on the density of the canopy and its twigs and trunks. To the mangrove this process is important because the amount of rain that effectively reaches the soil helps to reduce salinity in the environment and is determinant for the type of predominant species in the mangrove. This project counted on the financing of the CNPq, process referring number 470434/2006-6 to the proclamation MCT/CNPq 02/2006 - Universal.

Keywords: mangrove, climatic attributes, canopy, rainfall, interception.

\section{INTRODUÇÃO}

A área do Sistema Costeiro Cananéia-Iguape pode ser considerada uma das mais preservadas do Estado de São Paulo, devido à sua extensão e estágio de preservação. Possui uma complexa biodiversidade; rica em espécies aquáticas de elevado valor econômico, com extensas áreas de manguezais, restingas e Mata Atlântica, destaca-se por sua diversidade e produtividade.

Os manguezais, com importante destaque na área de estudo, caracterizam-se por ambiente salinizado e pela constante inundação causada por marés. Sua importância maior está relacionada à produção de biomassa, introduzida no sistema bioenergético natural, para aumentar a produtividade da zona costeira com a introdução de particulados orgânicos, nas águas estuarino-lagunares, 
pelos processos químicos e biológicos (HERZ, 1988). Representam comunidades vegetais adaptadas a várias condicionantes físicas atuantes nas zonas costeiras, entre elas, as climáticas.

A elevada biodiversidade característica do manguezal tem apresentado alterações significativas realizadas pela ação antrópica. Essas modificações alteram a cobertura vegetal, que por sua vez, altera o microclima. Atualmente, tem aumentado a preocupação sobre a possível irreversibilidade do impacto ambiental local e sua influência nos regimes hidrometeorológicos desse ambiente, ao mesmo tempo, em que se conhece pouco a respeito das respostas do manguezal às condições climáticas.

Estudos apontam o ecossistema manguezal como indicador biológico das variações climáticas globais e do aumento previsto do nível relativo do mar, como Snedaker et al., (1981) e Schaeffer-Novelli (2002).

A precipitação, juntamente com a temperatura do ar, possui papel de destaque na biogeografia do manguezal, com influência marcante na organização da distribuição do manguezal (Chapman, 1976). Ribeiro (2001) afirma que as precipitações tem repercussão na fisiologia das plantas halófitas e propriedades físicas dos solos, expostos as precipitações ou aos deflúvios extremos que reduzem a salinidade das águas no interior dos canais de drenagem das planícies costeiras. Assim, a pluviosidade é um dos atributos que mais contribui para o desenvolvimento dos manguezais.

Diante disso, esse artigo tem como objetivo apresentar a análise da precipitação no manguezal, bem como quantificar sua interceptação pelo dossel presente no ambiente de manguezal, localizado na Barra do Ribeira-Iguape/SP. Objetiva ainda, comparar e relacionar os valores obtidos no manguezal com os dados de uma estação meteorológica automática da rede oficial do Centro de Previsão do Tempo e Estudos Climáticos (CPTEC) distante 12,5 km da área de estudo.

\section{ÁREA DE ESTUDO}

O Sistema Costeiro Cananéia-Iguape é considerado um dos mais produtivos, em relação à produtividade primária e um dos principais locais de abrigo e reprodução de inúmeras espécies marinhas da costa sudeste brasileira. Ross (2002) classifica a área como Sistema da Planície Costeira CananéiaIguape. Segundo esse autor, essa região faz parte de uma importante área estuarina de grande complexidade biofísica, onde ocorrem os ecossistemas de mangues ao lado das planícies e cordões arenosos marinhos, recortados por planícies fluviais cujos sedimentos marinhos são retrabalhados pelos rios e acrescidos de outros sedimentos procedentes do interior do continente. Além disso, os terrenos arenosos são recobertos, aí depositados pelas fases de transgressão/regressão marinha (transgressões Cananéia e Santos), por uma densa cobertura vegetal de mata de porte médio, em grande parte preservada, acompanhada de franjas de vegetação de mangue que ocupam as planícies intertidais (Planícies de Mangue).

De acordo com Ross, op. cit., essa região é uma das mais preservadas do litoral paulista, embora haja relativa concentração demográfica em áreas pontuais como Iguape e Cananéia e faixas lineares de ocupação na Ilha Comprida na linha de costa das praias abertas para o oceano. 
A área de estudo está localizada ao sul do litoral do Estado de São Paulo, constituída, principalmente, pelo setor nordeste do Sistema Costeiro CananéiaIguape e drenada pelo curso inferior do Rio Ribeira de Iguape, sob as coordenadas 47030' W e 47022'W e 24038' e 24040' (figura 01).

A figura 01 apresenta o uso do solo e a vegetação da Barra do Ribeira Iguape/SP, elaborada a partir de fotografias aéreas, ano 2001, em que é possível visualizar a distribuição dos manguezais ao longo da foz do Rio Ribeira de Iguape.

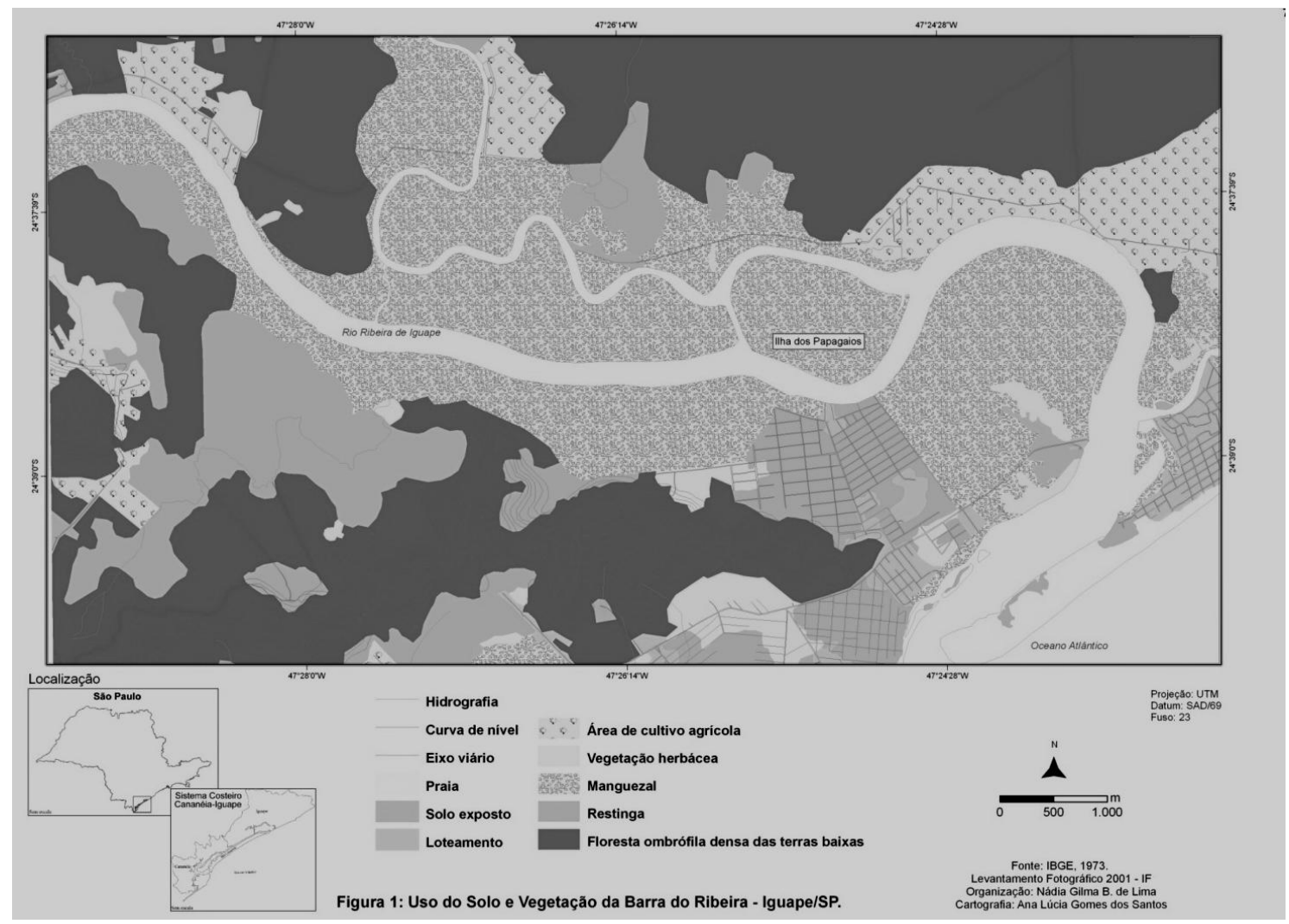

Quanto aos aspectos climáticos regionais, Gutjahr (1993) propôs uma compartimentação climática para a bacia do Rio Ribeira de Iguape, dividindo-a em dois compartimentos principais: Compartimento I, que compreendendo toda a Baixada do Ribeira, e consequentemente a Barra do Ribeira, e algumas porções serranas, como o Maciço da Juréia e a Serra de Itatins a NE e a Serra do Mar a SW. Embora seja esse o compartimento de altitudes mais rebaixadas, com algumas exceções, é essa a área de maior influência oceânica e com os maiores totais pluviométricos e temperaturas mais elevadas; Compartimento II - compreende todo o setor paranaense da bacia, abrangendo o alto curso e parte do médio curso do Rio Ribeira de Iguape, bem como toda a parte norte da bacia representada pela Serra de Paranapiacaba.

Sant'Anna Neto (1995) também propôs uma tipologia pluvial para o Estado de São Paulo, sendo o litoral classificado em litoral norte, central e sul. O litoral sul compreende a área situada entre Peruíbe e Cananéia, portanto compreende também o município de Iguape, eminentemente influenciada pelos sistemas extratropicais e frontais, que compensam uma provável diminuição dos 
totais pluviais por causa do afastamento da linha serrana. A precipitação anual varia entre 1.800 e $2.500 \mathrm{~mm}$, porém bem distribuída ao longo do ano por se tratar de área localizada sob os domínios do clima subtropical.

Para Monteiro (1973) e Tarifa (2004), o setor meridional do litoral paulista caracteriza-se também por uma maior variação da pluviosidade, em relação ao litoral norte, já que o afastamento da Serra de Paranapiacaba da linha de costa faz alternar a baixada do único tributário atlântico de parte do Estado de são Paulo - o Rio Ribeira de Iguape - com os pequenos maciços isolados (Itatins, Juréia e Ilha do Cardoso). Enquanto a unidade rítmica é caracterizada pelo maior índice de penetração das massas polares e passagens frontais, a distribuição quantitativa das chuvas varia de acordo com a topografia. A faixa mais úmida da costa e, sobretudo da face exposta dos maciços isolados cede lugar a uma faixa menos úmida ao longo do curso do Ribeira, voltando a aumentar na encosta da Serra de Paranapiacaba.

Tarifa (2004) classificou o clima regional como subtropical úmido, sem estação seca definida. Para esse autor, o total anual médio da pluviosidade é de $2.277,8 \mathrm{~mm}$, com o trimestre mais chuvoso concentrado de janeiro a março e o trimestre menos chuvoso de junho a agosto. A estação quente e chuvosa prolonga-se habitualmente de outubro a abril dentro de um regime de pressões atmosféricas mais baixas, enquanto a estação menos chuvosa, de maio a setembro, ocorre associada à maior freqüência dos sistemas anticiclônicos polares e tropicais atlânticos. Nesse período, o resfriamento de outono-inverno reduz as médias de temperatura para valores entre $20,2{ }^{\circ} \mathrm{C}$ (maio), sendo o mês mais frio julho, com $17,8{ }^{\circ} \mathrm{C}$. A radiação solar global registra um valor médio anual de $295,8 \mathrm{cal} \mathrm{cm}^{-2} \mathrm{dia}^{-1}\left(12,38 \mathrm{MJ}^{-2} \mathrm{~m}^{-2}\right.$. dia $\left.{ }^{-1}\right)$ enquanto que o mês com o máximo registrado é janeiro, com 406,6 cal cm $\mathrm{clia}^{-1}\left(17,02 \mathrm{MJ}^{-\mathrm{m}^{-2}}\right.$.dia $\left.{ }^{-1}\right)$ e mínimo mensal em julho com 193,9 $\mathrm{cal} \mathrm{cm}^{-2} \mathrm{dia}^{-1}\left(8,12 \mathrm{MJ}^{-\mathrm{m}^{-2}} \cdot \mathrm{dia}^{-1}\right)$.

Devido a localização muito próxima do oceano e a trajetória dos deslocamentos dos sistemas ciclônicos associados as ondulações da frente polar, a área está submetida a forte impactos pluviométricos, sendo o máximo mensal registrado o valor de $966,8 \mathrm{~mm}$, em fevereiro de 1960 e o máximo em 24 horas de 409,3 mm, em abril de 1973 (TARIFA, 2004).

\section{Os Manguezais}

O manguezal é um ecossistema costeiro, de transição entre os ambientes terrestres e marinhos, característico de regiões tropicais e subtropicais, sujeito ao regime das marés. Esse ambiente halófito, estabelecido sobre as zonas de entre marés, associa-se a cobertura vegetal típica, com desenvolvimento de flora especializada, caracterizada por espécies arbóreas que the conferem fisionomia peculiar (feição "mangue"), o qual exposto as lavagens diárias das marés exportam folhas, galhos, propágulos e material particulado, a ser decomposto nos corpos d'água adjacentes (rios, estuários, águas costeiras). Ocorrem em regiões abrigadas e apresenta condições propícias para alimentação, proteção e reprodução de muitas espécies de animais, sendo considerado importante transformador de nutrientes em matéria orgânica (SCHAEFFER-NOVELLI et al., 1995). De acordo com Schaeffer-Novelli et al. (2000), o termo manguezal refere-se ao ecossistema, enquanto mangue é utilizado para designar o grupo de espécies arbóreas com adaptações para sobreviver no ambiente entre-marés. 
Segundo Schaeffer-Novelli et al. (1995), o maior grau de desenvolvimento dos manguezais dependeria de cinco requisitos: (1) temperatura média do mês mais frio superior a $20^{\circ} \mathrm{C}$ e amplitude térmica anual maior que $5{ }^{\circ} \mathrm{C}$ (CHAPMAN, 1976); (2) sedimentos predominantemente lodosos, ricos em matéria orgânica; (3) áreas abrigadas contra tormentas; (4) presença de água salgada, pois as plantas de mangue são halófitas facultativas e assim ganham na competição com espécies terrestres não adaptadas a presença do sal no sedimento; (5) elevada amplitude de maré com reduzida declividade, o que permitiria a penetração de águas marinhas a grandes distâncias.

Blasco (1984) em suas considerações sobre a biogeografia do manguezal, refere-se que as espécies desaparecem quando a temperatura média do mês mais frio é inferior a $16^{\circ}$.

Vale (2004) ressalta que, com relação à distribuição latitudinal, em muitos lugares o comportamento em relação à temperatura do ar não é observado. Em Santa Catarina, por exemplo, a temperatura média do ar durante o inverno é inferior a $10^{\circ} \mathrm{C}$, assim como em outras localidades em latitudes mais elevadas. Todavia, a vegetação pode sofrer estresse, apresentando menor desenvolvimento estrutural e, muitas vezes, sendo representada apenas por Avicennia, gênero que resiste melhor as temperaturas mais frias.

Para Silva e Herz (1987) o manguezal tem uma característica de regulador térmico, devido ao acúmulo da radiação solar no substrato, cujo elevado conteúdo de água, constantemente renovado pelo efeito de maré, está sempre disponível para ser usado pelas plantas no processo de evaporação.

Ribeiro (2001) afirma que a precipitação tem repercussão na fisiologia das plantas halófitas e propriedades físicas dos solos, expostos as precipitações ou aos deflúvios extremos que reduzem a salinidade das águas no interior dos canais de drenagem das planícies costeiras. Para Ribeiro, op. cit., o dossel do manguezal e a atmosfera interagem dinamicamente através de processos físicos que produzem transportes de energia e massa. Portanto, todas as informações relacionadas a partição de energia radiante sobre o manguezal, são fundamentais para 0 entendimento destes processos que controlam o microclima do ambiente.

No Brasil a ocorrência dos manguezais se faz sobre as superfícies holocênicas resultantes dos últimos episódios representativos transgressivos / regressivos do mar sobre o continente. As superfícies geológicas relativamente jovens, em geral desenvolvidas nas bordas de terraços pleistocênicos de níveis mais altos, com destaque para sedimentos recentes, freqüentemente inundados pelas marés atuais, recebem em seu conteúdo volumes de matéria orgânica e argilo-minerais finos depositados a partir de suspensões que aderem às partículas arenosas do terraço. Tais ambientes de hidrodinâmica complexa, mas caracterizados em geral por índices de baixa energia agregam tais partículas que oferecem excelentes condições ao desenvolvimento das plântulas de mangue (HERZ, 1988).

Os mangues apresentam adaptações particulares em função dos fatores limitantes do seu ambiente. Dentre elas destaca-se o sistema radicular, altamente especializado e fisiologicamente adaptado. A necessidade do desenvolvimento de um sistema radicular que permaneça exposto à atmosfera em, pelo menos, uma parte do dia, está relacionada à natureza anaeróbica e inconsolidada dos substratos nos quais se desenvolvem (VALE, 2004). 
Odum (1967 18 apud Cintrón; Schaeffer-Novelli, 1985) enfatiza a elevada complexidade presente nos manguezais, mencionando que vários fatores, de diferentes naturezas, são responsáveis pelo desenvolvimento dos manguezais, como a maré, a energia solar, aporte de água doce e nutriente e que os fluxos dessas energias e materiais disponíveis contribuem para que o mangue se desenvolva mais ou menos, dependendo da intensidade e freqüência com que atuam essas forças. Segundo Schaeffer-Novelli et al. (2000), as características fisionômicas e funcionais dos padrões de manguezais refletem a resposta das espécies componentes a fatores ecofisiológicos locais.

\section{A ESCALA DE TRABALHO}

Devido à atenção dada atualmente aos estudos ambientais e com isso a necessidade de estudos em escalas inferiores do clima, com análises mais detalhadas, os estudos microclimáticos vem ganhando cada vez mais destaque. No entanto, apesar da atualidade dos estudos microclimáticos, os mesmos já vêm sendo desenvolvidos há algum tempo, conforme Geiger (1961).

O início da microclimatologia se deu por volta de 1893, quando Theodor Homén, na Finlândia efetuou medidas comparativas do balanço térmico em diferentes tipos de solo. No entanto, o botânico Gregor Kraus, em 1911, publicou o livro "Solo e clima nos espaços mais ínfimos", e é apontado como pai da microclimatologia. A microclimatologia nos seus fundamentos e aplicações práticas seria depois desenvolvida por Wilhem Schimidt (1883-1936), em Viena, e por August Schmaub (1877-1954), em Munique (GEIGER, op. cit.).

Geiger, op. cit., definiu a microclimatologia como sendo o estudo da camada de ar junto do solo e inferior a altura convencionada de $2 \mathrm{~m}$. Segundo Monteiro (1976), o próprio Geiger, mais adiante, flexionaria um pouco a rigidez do limite traçado, considerando-o apenas um referencial necessário a prática agrícola. Para esse autor, nessa camada estaria localizado, na maioria das vezes, as condições essencialmente mais diversas.

Segundo Geiger, op. cit., na proximidade do solo existem inúmeras diferenças entre todos os elementos meteorológicos, surgindo também diferenças horizontais em pequenas áreas, causadas pelas diversas características do solo e pelo tipo e altura da vegetação que o cobre. "Resumindo chama-se a todos esses climas de áreas muito reduzidas, microclima, por contraposição ao macroclima das redes nacionais" (GEIGER, op. cit, p. 06).

Para Stoutjesdijk e Barkman (1992), o microclima refere-se a interação que ocorre entre a superfície e os demais elementos climáticos (radiação solar, temperatura do solo e do ar, umidade, vento, etc.), ocorrendo de forma mais intensa nos $2 \mathrm{~m}$ mais inferiores da atmosfera e a 0,5 a $1 \mathrm{~m}$ no interior do solo, com a vegetação exercendo uma considerável influência nesse microclima. Para esses autores, o clima dentro da vegetação pode, ainda, ser chamado de ecoclima, podendo a diferença entre microclima e ecoclima ser explicada com o exemplo a seguir: em uma floresta alta o ecoclima pode se estender distante além do limite de $2 \mathrm{~m}$ do microclima, visto que em um ambiente livre da

${ }^{18}$ ODUM, H. T. Biological circuits and the marine systems of Texas. In: OLON, T. A.; BURGESS, F. J. Pollution and Marine Ecology. New York: John Wiley \& Sons Inc., 1967. p. 99-157. 
vegetação, por exemplo, um deserto, a rua da cidade ou o campo da neve, lá são ainda um microclima, mas nenhum ecoclima. Para micro e ecoclima é essencial que não somente os gradientes horizontais sejam estudados, mas também os verticais (WALLÉN 196919 apud STOUTJESDIJK; BARKMAN, 1992).

Tarifa (2002) faz uma ressalva às considerações de que microclima se refere, primeiramente, ao "clima próximo do solo", compreendendo os dois metros mais baixos da atmosfera, que é a necessidade de não se estabelecer limites rígidos para essa definição. Esse autor considera que os fluxos e insumos de energia de macroescala (astronômicos, planetários e regionais) são permanentemente utilizados, dissipados e transformados pelas diferentes formas de vida (biológica, humana e social) e de apropriação/produção do espaço, supondo que os controles meso, topo e microclimáticos, redefinam as ofertas, disponibilidades e ritmos.

Como referencial teórico, adotou-se para esse trabalho o conceito de microclima proposto por Geiger (1961) e que, segundo Stoutjesdijk e Barkman, op. cit., essa escala de trabalho é diretamente relevante à ecologia da vegetação, à distribuição e à dinâmica da população das plantas e dos animais.

Vários estudos vêm sendo desenvolvidos recentemente levando em consideração a escala microclimática, desde estudos de ambientes urbanos à estudos voltados a ecologia, a agricultura, a influência de lagos artificiais, visando a caracterização e derivações climáticas de diversos ambientes, dentre eles os manguezais, como Silva e Herz (1987); Silva (1991); Ribeiro (2001); Andrade et al. (2003); Ribeiro et al. (2003); Costa et al. (2005); Costa et al. (2006); Moura et al., (2006); Galvani e Lima (2006), entre outros.

\section{O DOSSEL DA VEGETAÇÃo COMO CONTROLE CLIMÁTICO.}

A vegetação é um dos principais controles climáticos para a determinação de microclima, já que estes estão essencialmente ligados ao uso e/ou cobertura do solo. A caracterização de uma cobertura vegetal em sua estrutura e distribuição espacial dos elementos vegetais representa o ponto de partida para o estudo de fenômenos físicos e fisiológicos que ocorrem em seu interior. Visto que a forma, a distribuição e a arquitetura do dossel contribuem diretamente para a quantidade de radiação solar incidente no ambiente em questão.

A estrutura dos bosques de mangue reflete as características e os hábitos de crescimento das espécies que o constituem. O grau de desenvolvimento que pode alcançar um bosque e sua composição específica é influenciado pelas energias subsidiárias do local. A partir da descrição estrutural pôde-se ter a idéia do grau de desenvolvimento, além de permitir a identificação e a delimitação de bosques, bem como a comparação entre si. Portanto, a fisionomia da comunidade vegetal reflete a densidade, o porte e a distribuição das espécies que a compõe. A estrutura do bosque varia ao longo do tempo determinando vários graus de maturidade. Os bosques jovens caracterizam-se por apresentar alta densidade de troncos de diâmetro reduzido, já os bosques

\footnotetext{
${ }^{19}$ WALLÉN, C. C. Definitions and scales in climatology as applied to agriculture. Proc. Regional Training Seminar on Agrometeorology. Wageningen: Agricultural Univ. Wageningen, p. 207-212, 1969.
} 
maduros caracterizam-se por apresentar uma baixa densidade de troncos, porém de diâmetro elevado.

Os bosques de mangue podem apresentar diferenças importantes em sua estrutura e funcionamento de acordo com a região, obedecendo a um grande número de fatores e processos ambientais (CUNHA-LIGNON, 2001).

A quantidade e a forma de orientação no espaço dos elementos vegetais são reflexos da estrutura, determinam a densidade de uma cobertura e constituem os fatores primários não só no regime de radiação como também nas trocas gasosas e energéticas entre o meio vegetal e a atmosfera (MARQUES FILHO, 1997).

A cobertura promovida pelo dossel controla a quantidade, qualidade e distribuição temporal e espacial da radiação solar que efetivamente atinge o solo, determinando níveis diferenciados de umidade do ar, temperatura e condições de umidade do solo, além de promover a interceptação das chuvas, reduzindo o impacto direto sobre o solo. Dessa forma, a cobertura é um dos determinantes do "micro-habitat" de uma floresta, afetando o crescimento e sobrevivência de plântulas, influenciando processos de oxidação da matéria orgânica e controlando processos erosivos (MELO et al., 2007), portanto a cobertura atua diretamente nas condições microclimáticas do ambiente.

\section{O ATRIBUTO CLIMÁtICO PLUVIOSIDADE}

A pluviosidade é um dos atributos que mais contribui para o desenvolvimento dos manguezais. De acordo com Chapman (1976), a precipitação, juntamente com a temperatura do ar, têm papel de destaque na biogeografia do manguezal, com influência marcante dessas variáveis para a organização da distribuição do manguezal. Ribeiro (2001) afirma que as precipitações tem repercussão na fisiologia das plantas halófitas e propriedades físicas dos solos, expostos as precipitações ou aos deflúvios extremos que reduzem a salinidade das águas no interior dos canais de drenagem das planícies costeiras.

No entanto, quando se fala no consumo de água por diferentes tipos florestais, freqüentemente o processo de interceptação da água da chuva pela cobertura florestal é ignorado, ou, quando muito, tratado como componente isolado do ciclo hidrológico (LIMA, 1983).

De acordo com Lima, op. cit., a interceptação é um processo extremamente importante na hidrologia de uma dada área, pois trata-se de um processo evaporativo que resulta em perdas de água que de outra forma chegaria ao solo, ilustra a importância dos fatores biológicos no ciclo da água, ou na hidrologia de uma bacia hidrográfica e a evaporação da água interceptada ocorre a uma taxa cerca de 2 a 3 vezes mais elevada do que a que ocorreria em condições de dossel seco o que implica, para um dado balanço de energia, que deve haver alguma forma de compensação na demanda de água do solo enquanto há interceptação.

Em florestas naturais ou plantadas, a quantidade de água de chuva que atinge o solo é denominada precipitação efetiva, dada pela precipitação interna e pelo escoamento pelo tronco (LIMA, 1976). Precipitação interna é a chuva que atinge o piso florestal, incluindo gotas que passam diretamente pelas aberturas entre as copas e gotas que respigam do dossel. A fração da chuva que é retida 
temporariamente pelas copas juntamente com aquela que atinge diretamente os troncos e que posteriormente escoam pelo tronco das árvores, chegando ao solo, é denominada escoamento tronco. A soma da precipitação interna e escoamento é um dos responsáveis pela água do solo (ARCOVA et al., 2003). Dessa forma, a precipitação efetiva é importante para os estudos dos processos de interceptação, infiltração, percolação, absorção, transpiração e ciclagem de nutrientes em ecossistemas florestais (OLIVEIRA JUNIOR et al, 2005).

\section{MATERIAIS E PROCEDIMENTOS}

\section{Levantamento dos Principais Atributos Climáticos}

O levantamento dos dados de precipitação ocorreu com a instalação de uma torre microclimática nos manguezais da Barra do Ribeira-Iguape/SP, mais especificamente na Ilha dos Papagaios, localizada na foz do Rio Ribeira de Iguape, que apresenta em toda a sua área $\left(1,5 \mathrm{~km}^{2}\right)$ a presença de manguezais. As coordenadas geográficas da torre microclimática são 24038'01,4" S e 47025'31,9'" W.

A torre microclimática apresenta uma estação meteorológica localizada a $2 \mathrm{~m}$ de altura em relação à superfície, contendo sensores de precipitação, temperatura do ar, umidade relativa do ar, radiação solar global, direção e velocidade do vento, visando obter os dados com a influência do dossel (figura 2), denominada de P02; e outra estação meteorológica, contendo os mesmos sensores que P02 e um saldo-radiômetro, denominada P10, instalada a $10 \mathrm{~m}$ de altura em relação a superfície, ultrapassando o dossel, para registrar os atributos climáticos antes da interferência da vegetação (figura 3).

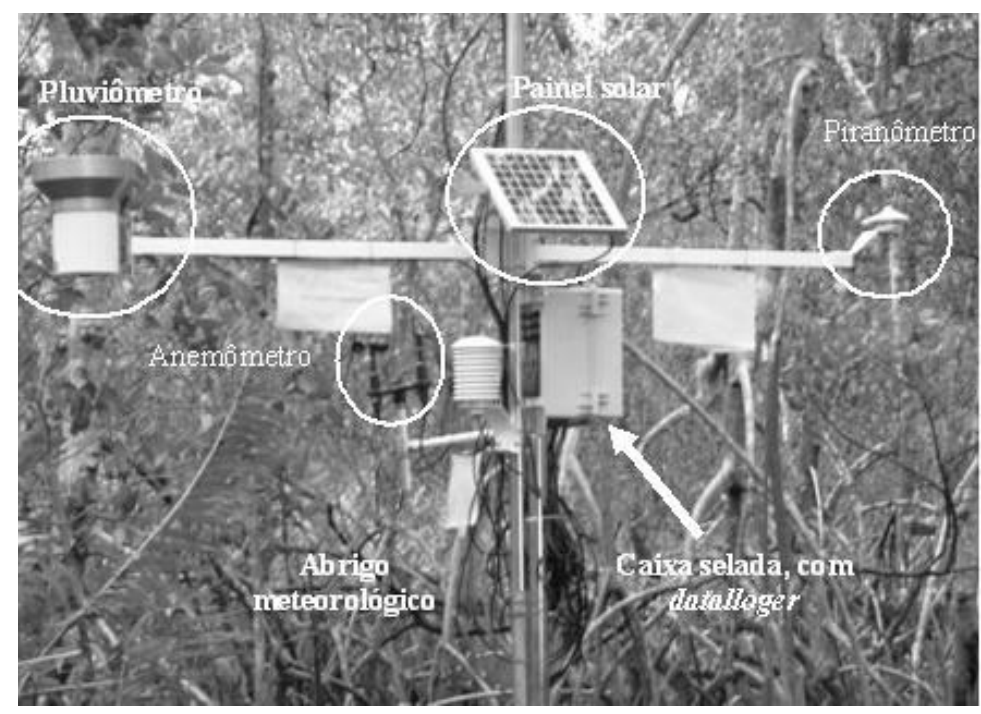

Figura 1: Equipamentos instalados abaixo do dossel de manguezal - Ilha dos Papagaios - Barra do Ribeira - Iguape/SP. (Autoria: Fernando Godoy, 2008). 


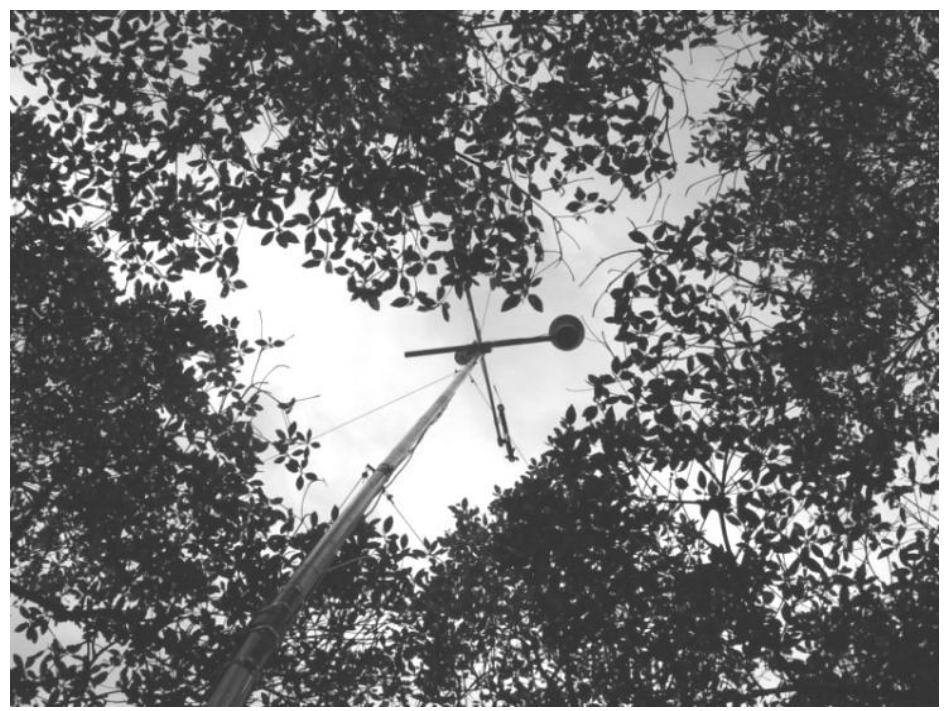

Figura 2: Equipamentos instalados no topo da torre microclimática - Ilha dos Papagaios - Barra do Ribeira/Iguape/SP. (Autoria: Nádia G. B. de Lima, 2008).

Os pluviômetros instalados na torre microclimática são do tipo TE525MML15, fabricados pela Texas Instruments, com registros a cada 10 min (figura 4a).

Para analisar a distribuição espacial do dossel ao longo da área de estudo, bem como contribuir com a análise da precipitação interna obtida dentro do ambiente manguezal foram instalados, em uma área de $400 \mathrm{~m}^{2}, 16$ pluviômetros confeccionados de acordo com os procedimentos determinados por Milanesi e Galvani (2005) para a confecção de pluviômetros para localidades remotas, de difícil acesso, cujo período de obtenção de dados refere-se a escala mensal (figura 4-b). Os pluviômetros foram distribuídos de forma que a torre microclimática se localizasse no centro da parcela. Ressalta-se que entender como se dá a distribuição espacial da chuva dentro de um ambiente como o manguezal, identificando os diferentes sítios existentes, contribui para melhor entendimento da germinação, da distribuição e do estabelecimento das espécies.

A figura 5 apresenta um croqui da parcela delimitada na área de estudo, utilizada na instalação dos pluviômetros totalizadores, em cada ponto identificado como P1, P2, P3 e P4, nas 4 parcelas, instalou-se um pluviômetro totalizador.

Para a quantificação da interceptação da pluviosidade no manguezal, foram analisados os eventos de precipitação de cada mês. Para a determinação desses eventos, considerou-se as precipitações com total superior a $1 \mathrm{~mm}$ e com intervalo de no mínimo 1 h entre o término e o início do próximo evento, no sensor P10. Esse procedimento foi adotado visando uma possível identificação de precipitação oculta, pois eventos inferiores a $1 \mathrm{~mm}$ podem estar associada a ocorrência de nevoeiro. A precipitação oculta pode ser definida como minúsculas partículas de neblina carregadas pelos ventos, que ao entrar em contato com o dossel pode ser interceptada. A precipitação total (PT) foi medida pelo sensor instalado a $10 \mathrm{~m}$ da superfície $(\mathrm{P} 10)$ e a precipitação interna (PI) pelo sensor a $2 \mathrm{~m}$ (P2) da superfície. 
a)

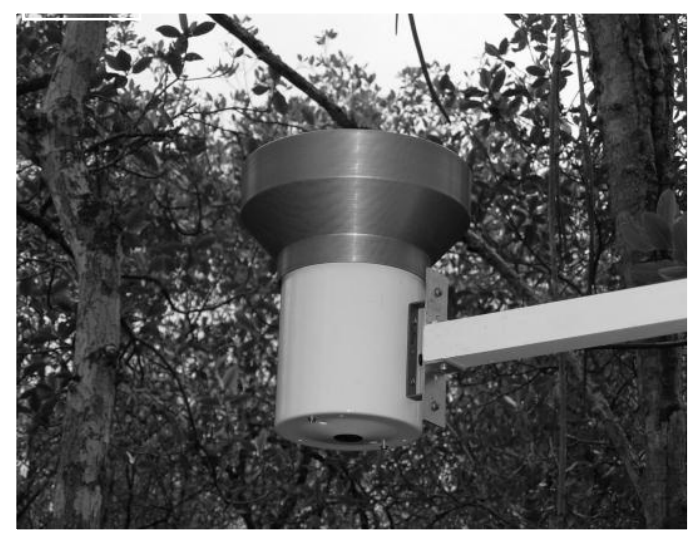

b)

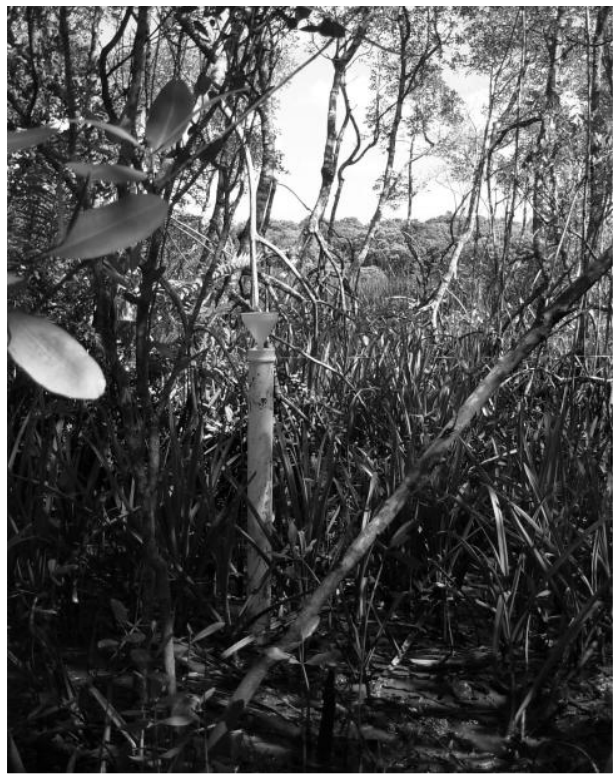

Figura 4: Pluviômetros instalados nos manguezais da Barra do Ribeira, a) tipo TE525MM-L15, b) pluviômetros para localidades remotas. (Autoria: Nádia G. B. de Lima, 2008)

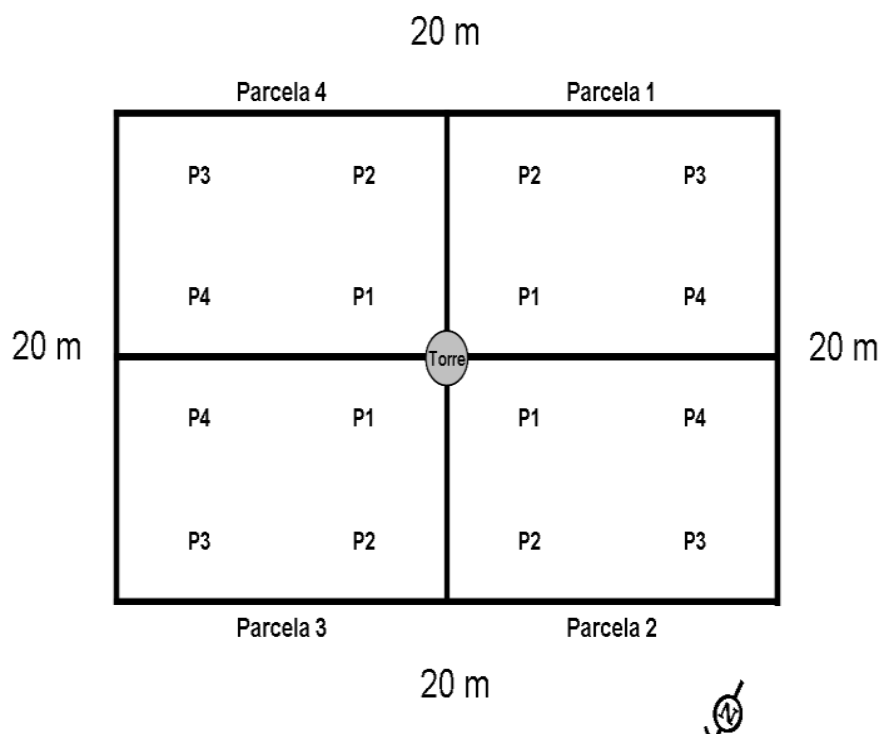

Figura 5: Croqui de delimitação da parcela de $400 \mathrm{~m}^{2}$ utilizada para disposição dos pluviômetros totalizadores.

A figura 6 apresenta um croqui da torre microclimática instalada no manguezal da Ilha dos Papagaios - Barra do Ribeira - Iguape/SP. O levantamento de dados ocorreu durante o período de 06/01 a 31/12/08. 


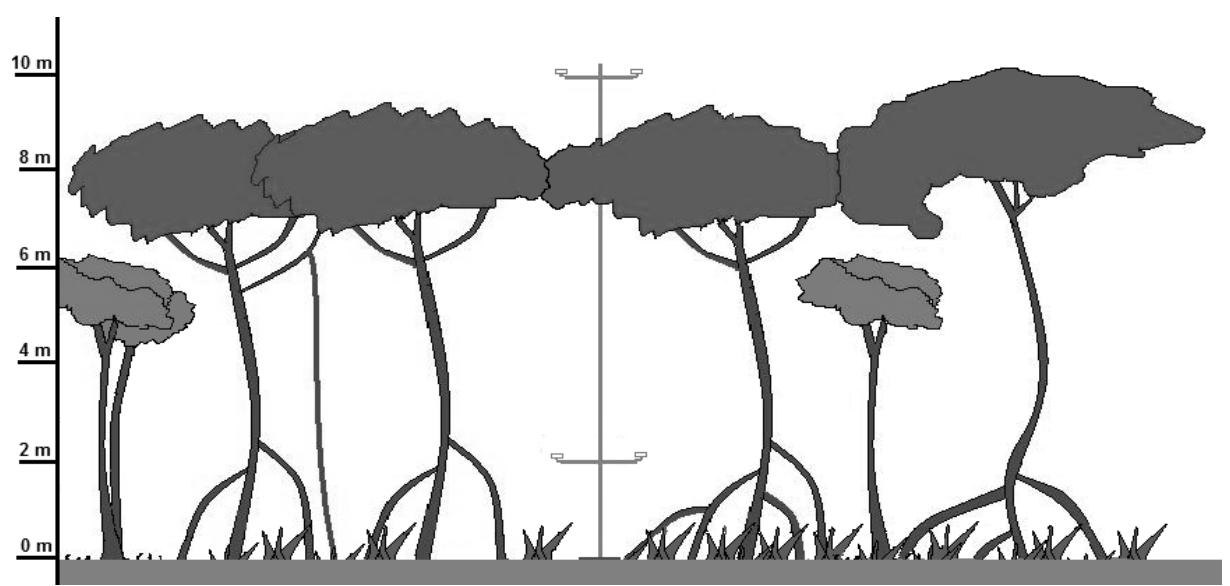

Figura 3: Croqui de instalação da torre microclimática - Ilha dos Papagaios Barra do Ribeira - Iguape/SP.

Visando comparar os registros dos atributos climáticos obtidos no manguezal com dados da rede oficial meteorológica, foram obtidos dados de precipitação da Estação Meteorológica Automática do Centro de Previsão do Tempo e Estudos Climáticos (CPTEC), a Plataforma de Coleta de Dados (PCD), de responsabilidade do Instituto Nacional de Pesquisas Espaciais (INPE). As PCDs, de acordo com o CPTEC, surgiram da necessidade de inúmeras empresas e instituições em obter regularmente informações registradas em locais remotos.

A PCD está localizada no Colégio Agrícola Narciso de Medeiros, no município de Iguape, sob as coordenadas geográficas $24,670 \mathrm{~S}$ e 47,540 W (Coordenada UTM 242.860 x 7.269.170), a uma altitude de $10 \mathrm{~m}$ e localizada a $12 \mathrm{~km}$ da Estação meteorológica instalada no manguezal da Barra do RibeiraIguape/SP. Por se tratar de uma estação meteorológica, a PCD apresenta-se instalada conforme as condições de referência para medidas meteorológicas e climatológicas (figura 07). Os dados de precipitação obtidos serão nesse artigo denominados de PPCD.

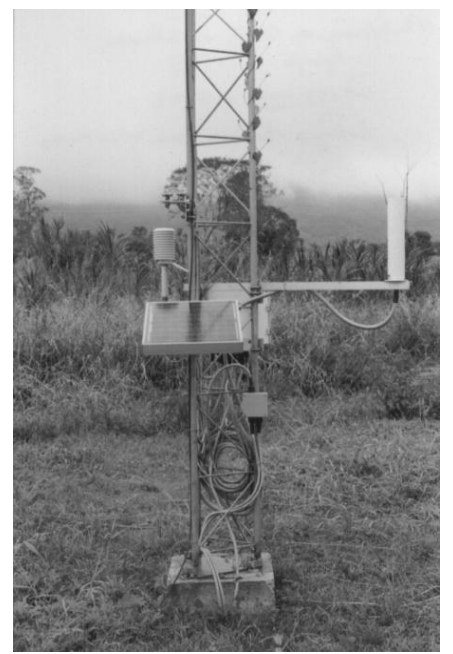

Figura 1: Plataforma de Coleta de Dados (CPTEC), localizada no município de Iguape/SP. (Autoria: Silvio Villar, 2005). 


\section{RESULTADOS E DISCUSSÃO}

\section{PLUVIOSIDADE MENSAL E SAZONAL}

A Tabela 01 apresenta a síntese dos dados de precipitação para P10 e PPCD. O total pluviométrico registrado em P10, durante o período de observações, 2008, foi de 1.981,5 mm. De acordo com Sant'Anna Neto (1995), a precipitação anual na região varia entre 1.800 a $2.500 \mathrm{~mm}$, enquanto Tarifa (2004) apresenta como média anual $2.277,8 \mathrm{~mm}$, portanto não diferenciando muito dos valores encontrados para esses autores. O mês de janeiro se destacou como o mês mais chuvoso, com um total de 509,3 mm, enquanto julho, com 19,6 mm, foi o mês menos chuvoso.

Tabela 1 - Precipitação $(\mathrm{mm})$ para 2008, obtida no manguezal da Barra do Ribeira - Iguape/SP e na Plataforma de Coleta de Dados - PCD.

\begin{tabular}{|c|c|c|c|c|c|c|}
\hline Meses & $\mathbf{P}_{\mathrm{PCD}}$ & $\begin{array}{c}\text { Máximo } 24 h \\
(\mathrm{~mm})\end{array}$ & P10 & $\begin{array}{c}\text { Máximo } 24 h \\
(\mathrm{~mm})\end{array}$ & $\begin{array}{c}\text { Desvio } \\
\text { Absoluto (mm) }\end{array}$ & $\begin{array}{c}\text { Desvio } \\
\text { Relativo (\%) }\end{array}$ \\
\hline J & 468,8 & 155,3 & 509,3 & 171,1 & $-40,5$ & $-8,0 \%$ \\
\hline $\mathrm{F}$ & 148,6 & 54,3 & 102,1 & 44,1 & 46,5 & $45,6 \%$ \\
\hline M & 272,0 & 75,5 & 257,3 & 87,9 & 14,7 & $5,7 \%$ \\
\hline A & 234,8 & 57,5 & 184,7 & 48,4 & 50,1 & $27,1 \%$ \\
\hline$M$ & 186,1 & 96,0 & 164,8 & 77,4 & 21,3 & $12,9 \%$ \\
\hline J & 92,2 & 32,0 & 88,7 & 30,0 & 3,5 & $4,0 \%$ \\
\hline J & 22,8 & 21,0 & 19,6 & 19,0 & 3,2 & $16,2 \%$ \\
\hline A & 190,3 & 46,0 & 169,8 & 42,1 & 20,4 & $12,0 \%$ \\
\hline $\mathrm{S}$ & 161,8 & 43,5 & 119,1 & 39,8 & 42,7 & $35,9 \%$ \\
\hline $\mathrm{O}$ & 205,3 & 55,8 & 125,0 & 25,9 & 80,3 & $64,2 \%$ \\
\hline $\mathrm{N}$ & 124,3 & 25,5 & 108,5 & 26,1 & 15,8 & $14,5 \%$ \\
\hline D & 145,1 & 25,2 & 132,7 & 25,8 & 12,4 & $9,3 \%$ \\
\hline Total & 2251,5 & & 1981,5 & & 270,2 & $13,6 \%$ \\
\hline
\end{tabular}

Em média, a precipitação na PPCD foi $13,6 \%$ maior do que no manguezal, com exceção de janeiro, onde a precipitação foi $8 \%$ maior no manguezal. O menor desvio relativo entre os sensores ocorreu em junho, com precipitação na PPCD $4 \%$ maior que no manguezal. O mês de outubro apresentou o maior desvio relativo, 64,2\%, ou seja, a PPCD apresentou precipitação superior em $64,2 \%$ que o manguezal.

A figura 08 apresenta a distribuição da precipitação obtida para P10 e PPCD. Observa-se que apesar da diferença entre os dados, os registros apresentam uma tendência semelhante de variação ao longo do ano. Constatouse que, com exceção de janeiro, a PPCD obteve os maiores totais pluviométricos.

A diferença entre os totais de precipitação deve-se a variação espacial da chuva em especial nos meses em que predominam chuvas de origem convectiva, como no mês de janeiro. Vale ressaltar, ainda, que a estação meteorológica do manguezal está localizada a $12,5 \mathrm{~km}$ de distância da torre microclimática instalada no manguezal.

O total máximo registrado em $24 \mathrm{~h}$ foi observado em janeiro, tanto no manguezal quanto na PPCD, 171,1 e 155,3 mm, respectivamente (Figura 09). 0 mês de julho apresentou como máximo registrado em $24 \mathrm{~h}$, para os dois sensores, 19 e $21 \mathrm{~mm}$, para P10 e PPCD, respectivamente. 


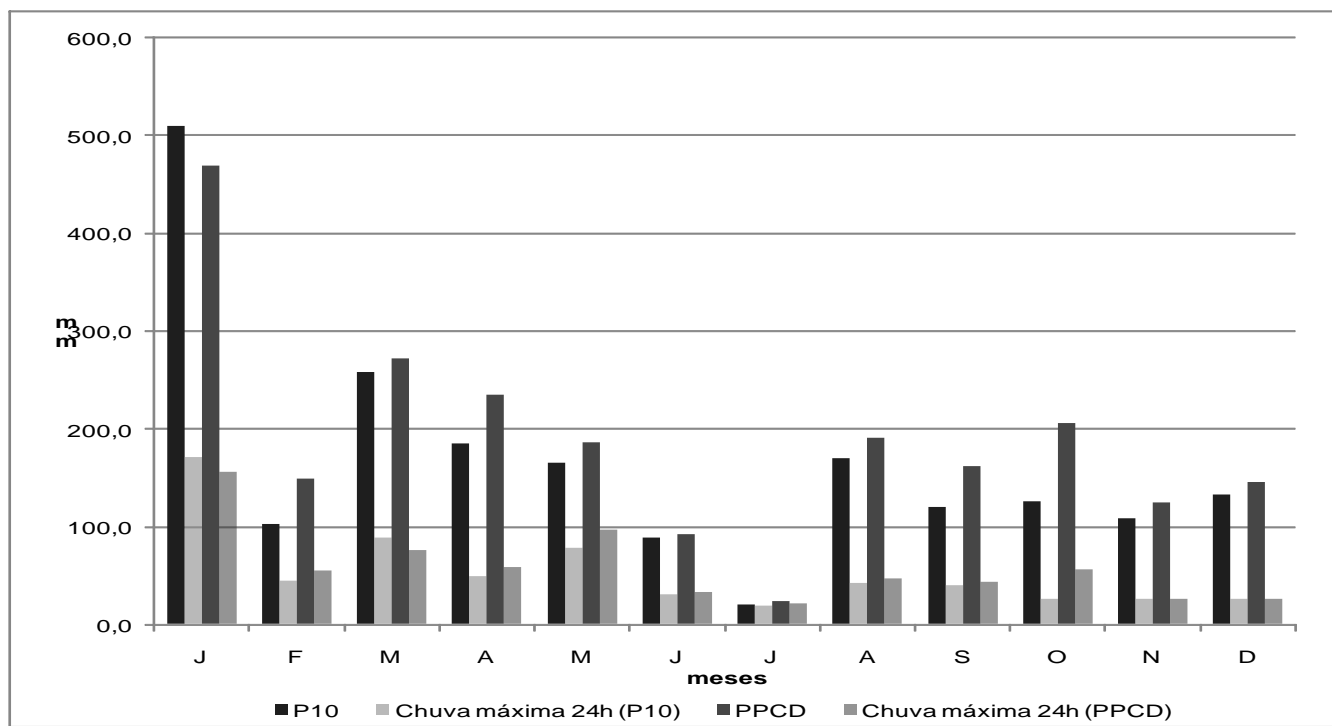

Figura 08: Pluviosidade total registrada para 2008 e total máximo em 24h para o manguezal (P10) e PCD - Ilha dos Papagaios - Barra do Ribeira - Iguape/SP.

Na figura 09 é possível visualizar o período de maior precipitação para o mês de janeiro, aqui em destaque devido ao elevado volume de precipitação, correspondente principalmente aos dias 12 e 13 de janeiro de 2008, quando choveu $290,4 \mathrm{~mm}$, o equivalente a $69 \%$ do total de janeiro e $15 \%$ do total anual.

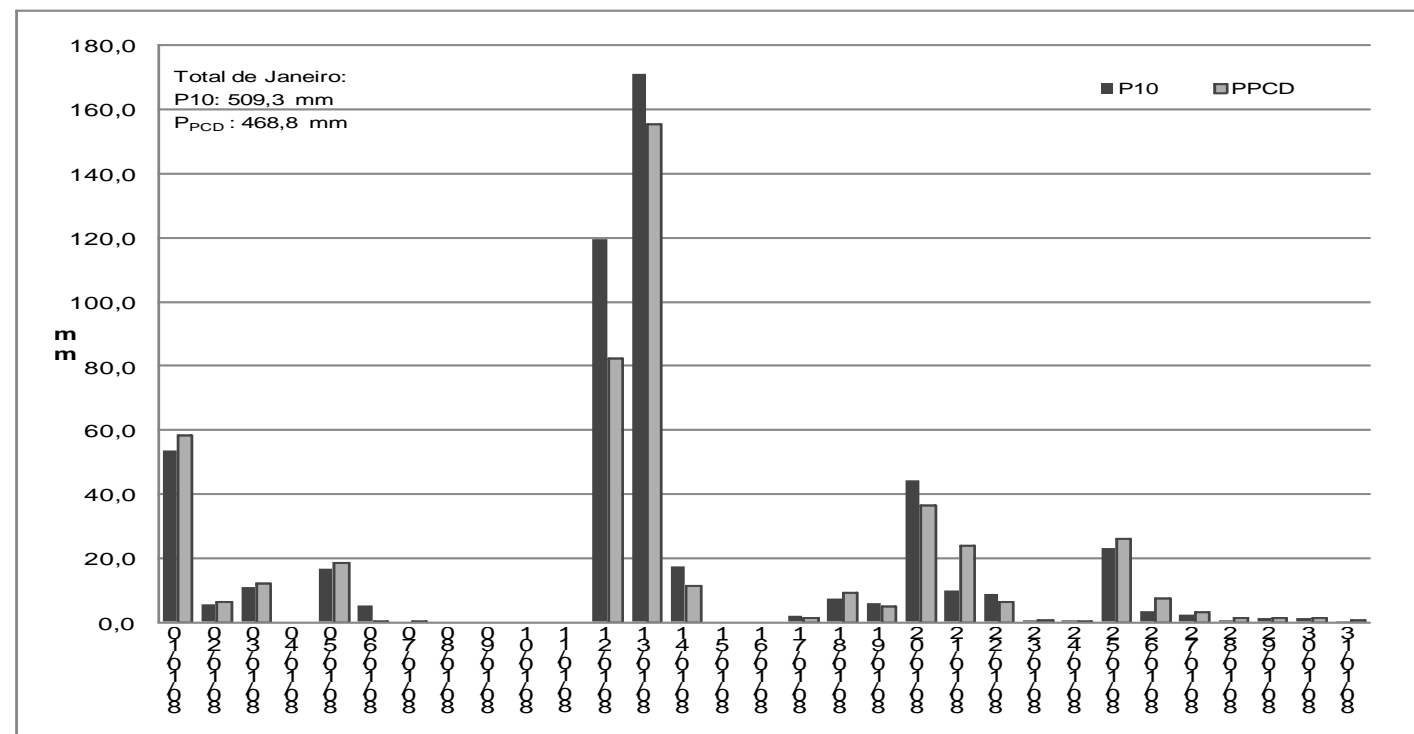

Figura 09: Pluviosidade total diária para janeiro, registrada no manguezal (P10) da Ilha dos Papagaios - Barra do Ribeira (10) e para a PPCD - Iguape/SP.

A figura 10 apresenta a relação entre a precipitação total diária (P10) e os dados da PPCD. No total foram 172 dias com ocorrência de precipitação. A análise de regressão linear simples mostra uma elevada correlação entre as variáveis, com coeficiente de determinação $\left(R^{2}\right)$ de 0,870 . Com obtenção dessa 
relação linear simples foi possível preencher as falhas no sensor P10 a partir dos dados da PPCD.

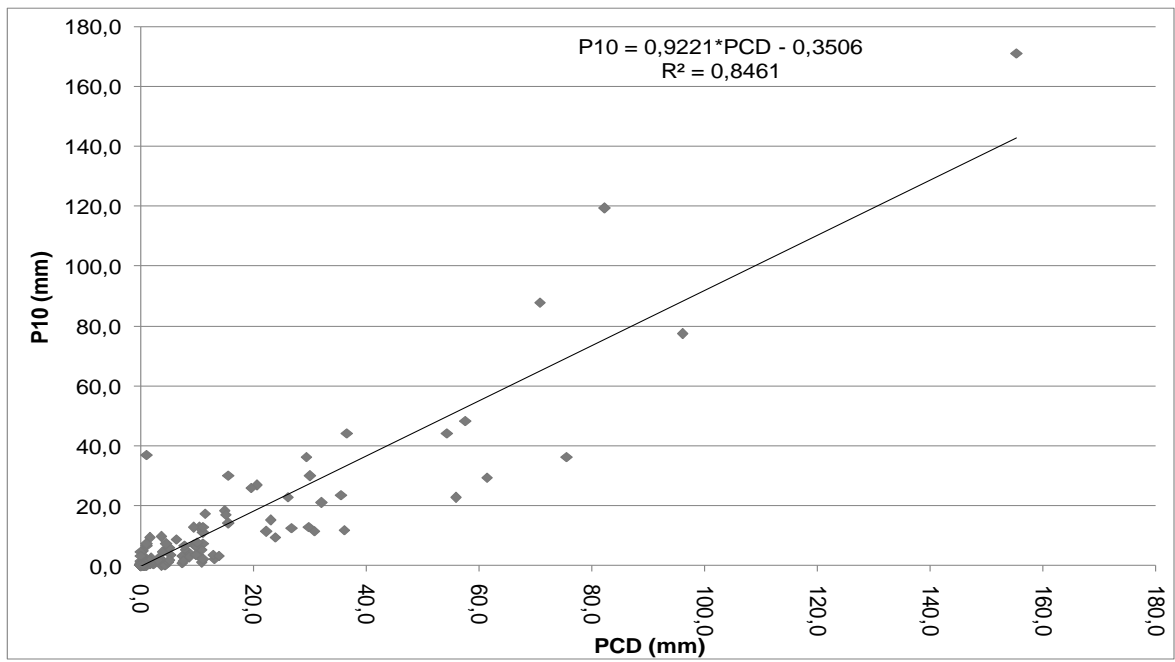

Figura 10: Coeficiente de determinação para a precipitação total diária obtida no manguezal (P10) da Ilha dos Papagaios - Barra do Ribeira e na PCD Iguape/SP.

Esse tipo de análise ganha importância quando da reconstituição de séries históricas pretéritas e futuras, ou seja, é possível após a retirada da estação experimental o entendimento das relações entre esses dois ambientes do ponto de vista pluviométrico, sem a necessidade de uma futura manutenção da estação meteorológica no ambiente.

A distribuição relativa dos totais sazonais da chuva para o manguezal no período em questão é apresentada na figura 11 .

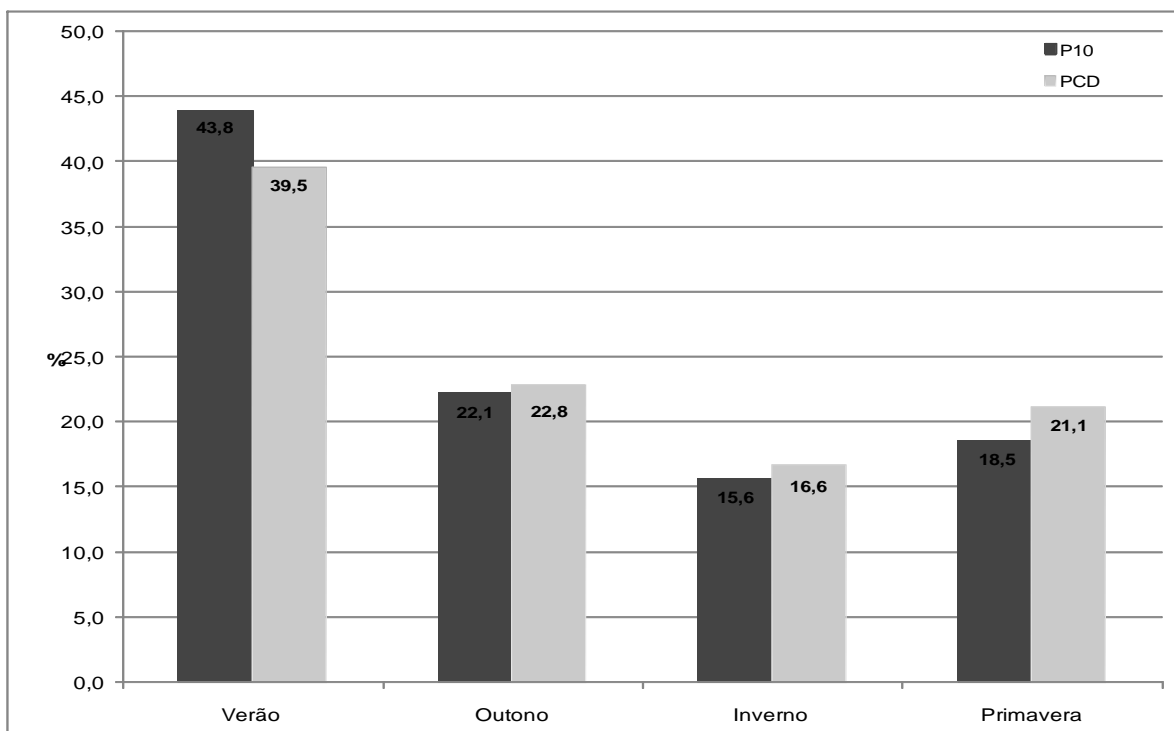

Figura 11: Distribuição sazonal da precipitação para $P 10$, localizado no manguezal da Ilha dos Papagaios - Barra do Ribeira, Iguape/SP. 
No verão, aqui definido como os meses de janeiro, fevereiro e março, registrou-se 868,6 mm, o que equivale a 43,8\% da precipitação total de 2008 . No outono (abril, maio e junho) foi registrado $22,1 \%$ da precipitação, com 438,2 $\mathrm{mm}$, enquanto o inverno (julho, agosto e setembro) apresentou o menor registro de precipitação, com 15,6\%, equivalente a $308,5 \mathrm{~mm}$, destacando-se como a estação menos chuvosa. A primavera (outubro, novembro e dezembro) foi a segunda estação menos chuvosa, com 366,2 mm, correspondendo a $18,5 \%$ do total precipitado. Observa-se que a PPCD, apresentou distribuição sazonal semelhante a do manguezal.

\section{INTERCEPTAÇÃO DA PLUVIOSIDADE PELA VEGETAÇÃO}

A relação entre precipitação total ou precipitação acima do dossel (P10) e a precipitação interna ou precipitação abaixo do dossel do manguezal (P02) são observadas na figura 12 . Verifica-se que a precipitação interna diária pode ser altamente correlacionada $\left(R^{2}=0,9807\right)$ com a precipitação total, como indica o modelo de regressão linear.

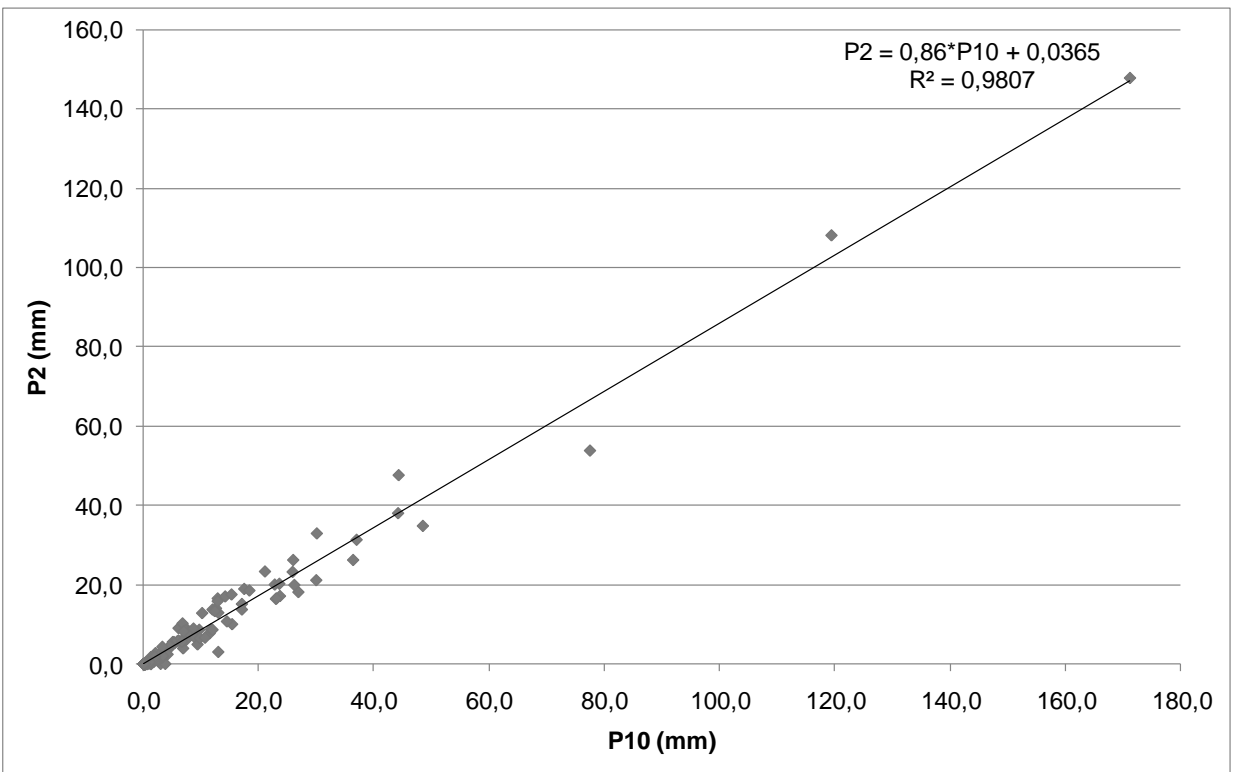

Figura 12: Coeficiente de determinação entre a precipitação total e a precipitação interna para o manguezal da Ilha dos Papagaios - Barra do Ribeira - Iguape/SP.

Conforme pode ser observado na tabela 02 , o período de análise para determinação da interceptação não ocorreu de forma contínua ao longo do ano. Observa-se que em fevereiro foi obtido dois períodos de análise, com 9 e 7 dias; março e setembro, com 10 dias cada. Além disso, janeiro e junho apresentam 26 e 23 dias de análise, respectivamente. Os demais meses apresentaram um período de um mês de dados. Esse período de análise registrou uma precipitação total de 1299,6 mm, com elevada amplitude de variação, com valores entre 1,0 mm (critério da autora) a 140, $2 \mathrm{~mm}$, registrada em 145 eventos de chuvas. 
Observou-se que janeiro e abril, com período de 26 e 30 dias, respectivamente, apresentaram 24 eventos de precipitação. No entanto, janeiro se destaca por apresentar um volume de chuva superior ao de abril, com redução de $56,8 \%$ em abril.

A tabela 02 apresenta ainda a precipitação total a 10m (P10); a precipitação registrada pelo sensor a $2 \mathrm{~m}$; a quantidade de precipitação que chegou ao sensor a $2 \mathrm{~m}$, oriunda de outras áreas de captação, através da concentração realizada por folhas e galhos (C); a precipitação interceptada pelo dossel do manguezal e que, portanto, não chegou ao substrato/solo do manguezal (I).

Tabela 02 - Período de análise, número de dias com chuva, números de eventos ( $\mathrm{N}$ o Eventos), P10 (mm), P02 (mm), Concentração (C, mm), Perda por Interceptação (I, $\mathrm{mm}$ ) e porcentagem de perda por interceptação (\%).

\begin{tabular}{|c|c|c|c|c|c|c|c|}
\hline Período & $\begin{array}{l}\text { Dias } \\
\text { com } \\
\text { chuva }\end{array}$ & $\begin{array}{c}\text { No } \\
\text { Eventos }\end{array}$ & P10 & P2 & $\mathbf{C}$ & $\mathbf{I} *$ & $\%$ \\
\hline 06 a & 14 & & & & & & \\
\hline $31 / 01 / 08$ & & 24 & 414,7 & 378,6 & 27,40 & 63,5 & 15,3 \\
\hline $\begin{array}{c}01 \mathrm{a} \\
09 / 02 / 08\end{array}$ & 3 & 4 & 14,9 & 11,1 & 0,90 & 4,7 & 31,5 \\
\hline $16 a$ & & & & & & & \\
\hline $22 / 02 / 08$ & 2 & 2 & 9,7 & 10,3 & 2,2 & 1,6 & 16,5 \\
\hline $22 \mathrm{a}$ & 5 & & & & & & \\
\hline $31 / 03 / 08$ & & 6 & 77,8 & 58,8 & 0,80 & 19,8 & 25,4 \\
\hline $01 \mathrm{a}$ & 12 & & & & & & \\
\hline $30 / 04 / 08$ & & 24 & 179,3 & 155,5 & 17,70 & 41,5 & 23,1 \\
\hline $01 \mathrm{a}$ & 9 & & & & & & \\
\hline $31 / 05 / 08$ & & 15 & 158,4 & 133 & 13,10 & 38,5 & 24,3 \\
\hline $01 \mathrm{a}$ & 6 & & & & & & \\
\hline $23 / 06 / 08$ & & 8 & 77,7 & 83,6 & 10,60 & 4,7 & 6,0 \\
\hline $20 a$ & 5 & & & & & & \\
\hline 21/09/08 & & 7 & 15,7 & 14,4 & 2,60 & 3,9 & 24,8 \\
\hline $01 \mathrm{a}$ & 10 & & & & & & \\
\hline $31 / 10 / 08$ & & 18 & 120 & 113 & 15,40 & 22,4 & 18,7 \\
\hline $01 \mathrm{a}$ & 10 & & & & & & \\
\hline $30 / 11 / 08$ & & 14 & 103,8 & 94 & 11,60 & 21,4 & 20,6 \\
\hline $01 \mathrm{a}$ & 14 & & & & & & \\
\hline $31 / 12 / 08$ & & 23 & 127,6 & 100,9 & 5,80 & 32,5 & 25,5 \\
\hline Total & 90 & 145 & 1299,6 & 1153,20 & 108,10 & 254,5 & - \\
\hline
\end{tabular}

* Concentração $(\mathrm{C})=(\mathrm{P} 10-\mathrm{P} 02)<0=\mathrm{C}$; ${ }^{*}$ Interceptação $(\mathrm{I})=(\mathrm{P} 10-\mathrm{P} 02)>0=\mathrm{I}$; Análise válida para chuva na escala de $10 \mathrm{~min}$.

A interceptação média da pluviosidade para o ambiente manguezal foi de $19,6 \%$ ao longo do período. Constatou-se que o sensor localizado a $2 \mathrm{~m}$ registrou precipitação oriunda de outras áreas de captação através da concentração (C) realizadas por folhas e galhos (P02), resultado da arquitetura do dossel e do formato das folhas de mangue, o que em muitos momentos fez com que P02 apresentasse valores superiores a P10. Em média essa concentração realizada por folhas e galhos, correspondeu a 9,4\% do total registrado em P02. 
Ao comparar a interceptação ocorrida nos meses de janeiro e abril, com mesma quantidade de eventos de chuva, constatou-se que abril apresenta uma interceptação de $23,1 \%$ enquanto em janeiro a interceptação corresponde a $15,3 \%$ do total desse mês, evidenciando que o tipo de chuva influência na interceptação, ou seja, em janeiro predominam chuvas convectivas, com intensidade elevada, e abril com maior probabilidade de ocorrência de chuvas frontais, com intensidade moderada a fraca. Os menores registros de eventos de precipitação ocorreu no período de 16 a 22/02/08, com 2 eventos de precipitação, correspondendo a $16,5 \%$ de interceptação.

Os meses representativos da primavera (outubro, novembro e dezembro), com período de análise de um mês, apresentaram destaque para dezembro que apresentou 23 eventos, com o maior valor de interceptação, com $25,8 \%$. Enquanto outubro e novembro apresentaram 10 eventos de precipitação cada um, com 18,7 e 20,6 de interceptação, respectivamente.

Conforme pode ser observado na figura 13, há uma elevada correlação entre a P10 e P02 para janeiro, com coeficiente de determinação $\left(R^{2}\right)$ de 0,9439 . Constatou-se que durante janeiro, um mês considerado chuvoso, houve registros em que a precipitação no sensor P02 apresentava-se superior ao sensor $\mathrm{P} 10$, o que pode ser explicado pelas características estruturais da vegetação de manguezal, contribuindo para que a precipitação fosse redistribuída ao longo das folhas e galhos e que haja concentração para o sensor P2. Verificou-se que essa tendência ocorreu durante todo o período de observação.

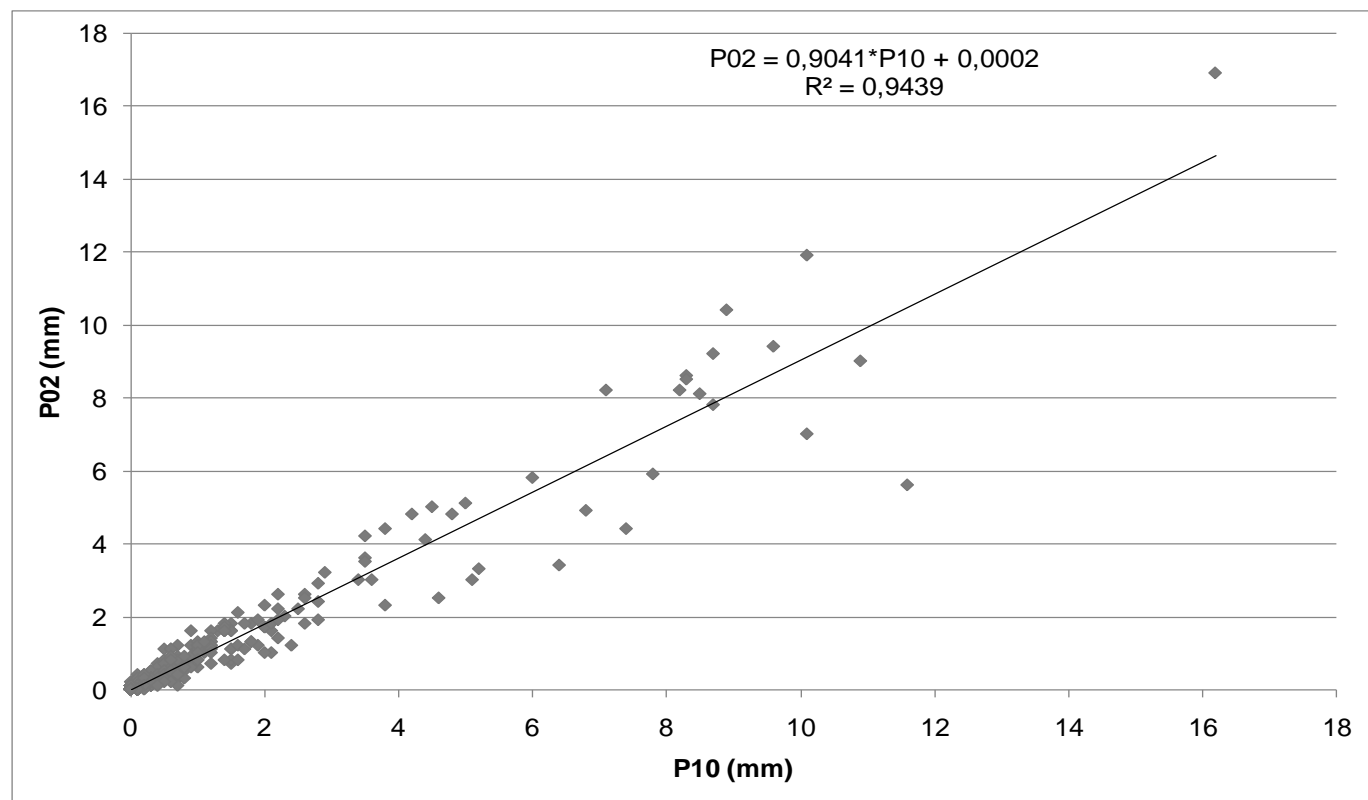

Figura 4: Coeficiente de correlação entre a precipitação total e a precipitação interna para janeiro no manguezal da Ilha dos Papagaios - Barra do Ribeira Iguape/SP.

Portanto, a interceptação no ambiente manguezal varia de acordo com o aspecto estrutural da vegetação, bem como com o regime de precipitação dominante. A quantidade de precipitação que efetivamente atinge o solo e a forma com que ela é redistribuída dentro do ambiente depende da densidade do 
dossel e de suas ramificações de galhos e caule. Para o manguezal esse processo é muito importante, visto que a quantidade de chuva que efetivamente atinge o solo contribuir para a diminuição da salinidade presente no ambiente, sendo determinante para o tipo de espécie predominante no manguezal.

Vários autores analisaram a interceptação vegetal. Costa, et. al (2006) observou que a taxa média de interceptação de chuva para uma floresta tropical chuvosa na Amazônia foi de 18,2\%, variando de um total médio de 14,6\% durante a época chuvosa (fevereiro) até um valor de 3,6\% durante a época menos chuvosa (novembro). Esta sazonalidade na variação da interceptação deve-se, principalmente, as diferentes características das precipitações, associadas com a dinâmica do vento naquela região. ARCOVA et al. (2003), trabalhando em floresta de secundária de Mata atlântica concluiu que, em média, $18,6 \%$ da precipitação foi interceptada pela floresta, retornando à atmosfera na forma de vapor. Oliveira Junior et al (2005) também trabalhando com fragmento de Mata Atlântica secundária concluiu que a perda por interceptação representa $18,3 \%$ da precipitação total.

\section{DISTRIBUIÇÃO ESPACIAL DA PRECIPITAÇÃO ABAIXO DO DOSSEL}

Conforme apresentado na tabela 03 e figura 14, constatou-se que a distribuição da precipitação ao ultrapassar o dossel do manguezal ocorre de forma diferenciada, resultado da diferente arquitetura e densidade do dossel. Observa-se, ainda, que os locais de instalação dos pluviômetros totalizadores acumularam uma quantidade considerável de precipitação por concentração de folhas e galhos.

Tabela 03 - Pluviosidade registrada pelos pluviômetros distribuídos ao longo das 4 parcelas, P10 e P2.

\begin{tabular}{ccccccc}
\hline Data & $\begin{array}{c}\text { Parcela } \\
\mathbf{1}\end{array}$ & $\begin{array}{c}\text { Parcela } \\
\mathbf{2}\end{array}$ & $\begin{array}{c}\text { Parcela } \\
\mathbf{3}\end{array}$ & $\begin{array}{c}\text { Parcela } \\
\mathbf{4}\end{array}$ & $\mathbf{P 2}$ & $\mathbf{P 1 0}$ \\
\hline $\begin{array}{c}15 / 02 \mathrm{a} \\
21 / 03 / 08\end{array}$ & 308,6 & 250,7 & 248,6 & 235,9 & 219,5 & 251,7 \\
$\begin{array}{c}22 / 03 \mathrm{a} \\
11 / 04 / 08\end{array}$ & 215,5 & 126,1 & 126,7 & 151,1 & 97,9 & 126,8 \\
$\begin{array}{c}12 / 04 \mathrm{a} \\
24 / 05 / 08\end{array}$ & 450,9 & 321,7 & $386,3 *$ & $386,3 *$ & 227,3 & 278,5 \\
$\begin{array}{c}24 / 05 \mathrm{a} \\
11 / 07 / 08\end{array}$ & 141,5 & 208,3 & 418,7 & 335,5 & 123,6 & 116,9 \\
$\begin{array}{c}11 / 07 \mathrm{a} \\
20 / 09 / 08\end{array}$ & 356,3 & 315,0 & 257,1 & 386,5 & 249,9 & 285,7 \\
$20 / 09 \mathrm{a}$ & & & & & & \\
$31 / 10 / 08$ & 218,5 & 149,0 & 136,9 & 126,7 & 133,8 & 125,3 \\
$31 / 10 \mathrm{a}$ & & & & & & \\
$12 / 12 / 08$ & 219,5 & 172,2 & 138,9 & 255,9 & 134,6 & 155,8 \\
\hline Total & $\mathbf{1 9 1 0 , 9}$ & $\mathbf{1 5 4 3 , 0}$ & $\mathbf{1 7 1 3 , 2}$ & $\mathbf{1 8 7 8 , 0}$ & $\mathbf{1 1 8 6 , 6}$ & $\mathbf{1 3 4 0 , 7}$ \\
\hline
\end{tabular}

* Valores preenchidos pela média do período nas parcelas 1 e 2 .

Observa-se a Parcela 1 registrou a precipitação interna mais elevada. A Parcela 3 e 4, apresentaram valores elevados de precipitação. Enquanto o 
sensor P02 registrou os menores valores. Isso ocorre devido P02 estar localizado no limite entre dois dosséis, enquanto os demais pluviômetros estavam localizados mais ao centro do dossel. No entanto, apesar dessa diferença entre os pluviômetros, vale ressaltar que independente do sitio que estavam localizados, a vegetação do mangue contribuiu para que houvesse concentração de água da chuva nos pontos em que estão localizados.

$20 \mathrm{~m}$
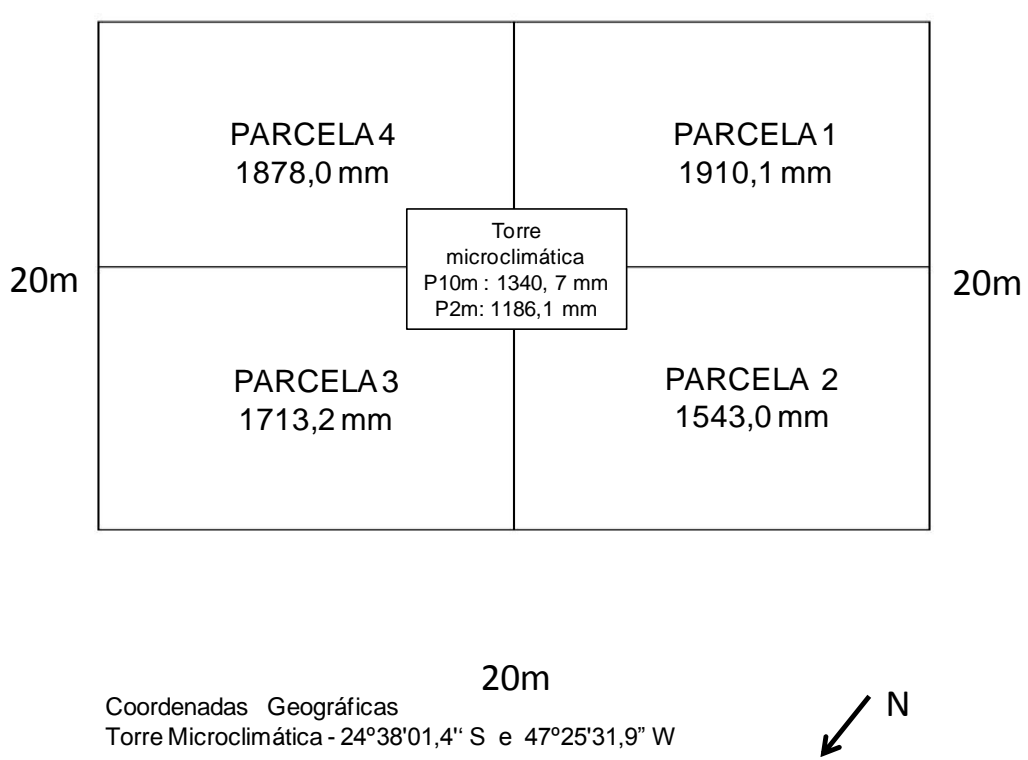

Figura 14: Disposição dos pluviômetros totalizadores em uma parcela de $400 m^{2}$ - Ilha dos Papagaios - Barra do Ribeira - Iguape/SP. Situação sem escala.

\section{CONCLUSÃO}

A interceptação média da pluviosidade para o ambiente manguezal foi de $19,6 \%$ ao longo do período. Constatou-se que o sensor localizado a $2 \mathrm{~m}$ registrou precipitação oriunda de outras áreas de captação através da concentração realizadas por folhas e galhos, resultado da arquitetura do dossel e do formato das folhas do mangue, o que em muitos momentos fez com que se registrassem valores superiores abaixo do dossel em relação a P10. Portanto, a interceptação no manguezal varia de acordo com o aspecto estrutural da vegetação, bem como com o regime de precipitação dominante. A quantidade de precipitação que efetivamente atinge o solo e a forma com que ela é redistribuída dentro do ambiente depende da densidade do dossel e de suas ramificações de galhos e caule. Para o manguezal esse processo é importante, visto que a quantidade de chuva que efetivamente atinge o solo contribuir para a diminuição da salinidade presente no ambiente, sendo determinante para o tipo de espécie predominante no manguezal.

É importante ressaltar, que entender como se dá a distribuição espacial da chuva dentro de um ambiente como o manguezal, identificando os diferentes 
sítios existentes, contribui para melhor entendimento da germinação, da distribuição e do estabelecimento das espécies arbóreas. A variabilidade espacial da precipitação tem papel importante dentro da distribuição das espécies de manguezal, contribuindo para a redução da salinidade a que este ambiente está exposto.

\section{REFERÊNCIAS}

ANDRADE V. M. S. et al. A influência da degradação dos manguezais no microclima. In: CONGRESSO BRASILEIRO DE AGROMETEOROLOGIA, 13., 2003, Santa Maria. Anais... Santa Maria: Sociedade Brasileira de Agrometeorologia, 2003. p. 101-102.

ARCOVA, F. C. S.; CICCO, V. de; ROCHA, P. A. B. Precipitação efetiva e interceptação das chuvas por floresta de Mata Atlântica em uma microbacia experimental em Cunha - São Paulo. Revista Árvore, Viçosa-MG, v. 27, n. 2, p. 257-262, 2003.

BLASCO, F. Climatic factors and the biology of mangrove plants. In: SNEDAKER, S. C.; SNEDAKER, J. G. (Org.) The mangrove ecosystem: research methods. Paris: UNESCO, 1984. p. 18-35.

CENTRO DE PREVISÃO DE TEMPO E ESTUDOS CLIMÁTICOS. Apresenta dados de previsão do tempo e estudos climáticos do Brasil. Disponível em: <http://www.cptec.inpe.br>. Acesso em: 31 de março/2009; 24 de junho/09; 30 de outubro/08 e 26 de dezembro/08.

CHAPMAN, V. J. Mangrove vegetation. Vaduz: J. Cramer, 1976. 447p.

CINTRÓN, G.; SCHAEFFER-NOVELLI, Y. Características y desarrollo estructural de los manglares de Norte y Sur América. Ciência Interamericana, Washington, v. 25, n.1-4, p.4-15, 1985.

GEIGER, R. Manual de microclimatologia: o clima da camada de ar junto do solo. 4. ed. Lisboa: Fundação Calouste Gulbenkian, 1961. 556p.

GUTJAHR, M. R. Critérios Relacionados a compartimentação climática de bacias hidrográficas: A Bacia do Rio Ribeira de Iguape. 1993. 148 f. Dissertação (Mestrado em Geografia Física) - Faculdade de Filosofia, Letras e Ciências Humanas, Universidade de São Paulo, São Paulo. 1993.

HERZ, R. Distribuição dos padrões espectrais associados a estrutura física dos manguezais de um sistema costeiro subtropical. 1988. 378f. Tese (Livre Docência) - Instituto Oceanográfico, Universidade de São Paulo, São Paulo, 1988.

LIMA, W. P. Precipitação efetiva e interceptação em florestas de pinheiros tropicais e em reserva de cerradão. IPEF, Piracicaba, n. 24, p. 43-46, ago.1983. 
LIMA, W. P. Interceptação da chuva em povoamento de eucaliptos e pinheiros. IPEF, Piracicaba, n. 13, p. 75-90, 1976.

GALVANI, E; LIMA, N. G. B. Caracterização microclimática dos manguezais da Barra do Ribeira - Iguape/SP e suas relaçãoes com os aspectos fisionômicos da vegetação. Revista GEOUSP - Espaço e Tempo, São Paulo, No 20, p. 79 a 100. 2006

MILANESI, M. A.; GALVANI, E.. Pluviômetro experimental para localidades remotas. In: SIMPÓSIO BRASILEIRO DE GEOGRAFIA FÍSICA APLICADA, 11., 2005, São Paulo. Anais... São Paulo: Universidade de São Paulo, 2005. p. 1991-1997.

MONTEIRO, C. A. F. A dinâmica climática e as chuvas no Estado de São Paulo: estudo geográfico sob forma de Atlas. São Paulo: Instituto de Geografia, Universidade de São Paulo, 1973. 130 p.

MOURA, M. A. L. et al. Alguns aspectos da interação da maré e precipitação na variação sazonal da temperatura do solo em um manguezal tropical. In: CONGRESSO BRASILEIRO DE METEOROLOGIA, 14., 2006, Florianópolis. Anais... Florianópolis: Sociedade Brasileira de Meteorologia, 2006a.

MOURA, M. A. L. et al. Estudo da transferência da radiação solar em uma floresta de mangue em Alagoas. In: CONGRESSO BRASILEIRO DE METEOROLOGIA, 14., 2006, Florianópolis. Anais... Florianópolis: Sociedade Brasileira de Meteorologia, 2006b.

RIBEIRO, J. B. M. Micrometeorologia do manguezal e o impacto do desmatamento em Bragança-PA. 2001. 103 f. Tese (Doutorado em Engenharia Ambiental) - Escola de Engenharia de São Carlos, Universidade de São Paulo, São Carlos, 2001.

RIBEIRO, J. B. M.; ROCHA, E. J. P. da; FERREIRA, M. A. V. Análises preliminares sobre o microclima do manguezal de Bragança-PA. In: CONGRESSO BRASILEIRO DE AGROMETEOROLOGIA, 13., 2003, Santa Maria. Anais... Santa Maria: Sociedade Brasileira de Agrometeorologia, 2003.

ROSS, J. L. S. A morfogênese da bacia do Rio Ribeira do Iguape e os sistemas ambientais. Revista GEOUSP - Espaço e Tempo, São Paulo, n. 12, p. 21- 26, 2002.

SANT'ANNA NETO, J. L. As chuvas no Estado de São Paulo: contribuição ao estudo da variabilidade e tendência da pluviosidade na perspectiva da análise geográfica. 1995. 253 f. Tese (Doutorado em Geografia Física) - Faculdade de Filosofia, Letras e Ciências Humanas, Universidade de São Paulo, São Paulo, 1995.

SCHAEFFER-NOVELLI, Y. et al. Manguezal: ecossistema entre a terra e o mar. São Paulo: Caribbean Ecological Research, 1995. 64p. 
SCHAEFFER-NOVELLI, Y. et al. Brazilan Magroves. Aquatic Ecosystem Health and Management, n. 3, p. 561-570. 2000.

SCHAEFFER-NOVELLI, Y. Mangroves as indicators of sea level change in the muddy coasts of the world. In: HEALY, T.; WANG, Y.; HEALY, J. A. Muddy coasts of the world. Amsterdam: Elsevier Science, 2002.

SILVA, J. F.; HERZ, R. Estudo de microclimas em ambientes de manguezais na região do complexo estuarino-lagunar de Cananéia. In: SIMPÓSIO SOBRE ECOSSISTEMAS DA COSTA SUL E SUDESTE BRASILEIRA, 1., 1987, Cananéia. Anais... Cananéia: Academia de Ciências do Estado de São Paulo, 1987. p.127131.

SILVA, J. F. Ensaios sobre o balanço de radiação no ambiente costeiro: Sistema Estuarino-Lagunar Cananéia-Iguape. 1991. 152 f. Tese (Doutorado em Geografia Física) - Faculdade de Filosofia, Letras e Ciências Humanas, Universidade de São Paulo, São Paulo, 1991.

SNEDAKER, S. C.; JIMENEZ, J. A.; BROWNS, M. S. Anomalous aerial roots in Avicennia germinans (L). Bulletin of Marine Science, Flórida, v. 31, n. 2, p. 467-470, 1981.

STOUTJESDIJK, Ph; BARKMAN, J.J. Microclimate, vegetation e fauna. Uppsala/Suécia: Opulus Press AB, 1992. p. 216.

TARIFA, J. R. Os climas nos maciços litorâneos da Juréia-Itatins: um ensaio de ritmanálise. 2002. Tese (Livre Docência) - Faculdade de Filosofia, Letras e Ciências Humanas, Universidade de São Paulo, São Paulo, 2002.

Unidades climáticas dos maciços litorâneos da Juréia-Itatins. In: MARQUES, O. A. V.; DULEBA, W. (Org.). Estação Ecológica Juréia-Itatins: Ambiente Físico, Flora e Fauna. São Paulo: Holos, 2004. p. 42-50.

VALE, C. C. do. Séries geomórficas costeiras do Estado do Espírito Santos e os habitats para o desenvolvimento dos manguezais: uma visão sistêmica. 2004. 386 f. Tese (Doutorado em Geografia Física) Faculdade de Filosofia, Letras e Ciências Humanas, Universidade de São Paulo, São Paulo, 2004. 